\title{
Preparation of Li-Co-O film by metal organic chemical vapor deposition
}

\author{
Hirokazu KATSUI, ${ }^{\dagger}$ Yuji YAMASHITA, ${ }^{*}$ Rong TU and Takashi GOTO \\ Institute for Materials Research, Tohoku University, 2-1-1 Katahira, Aoba-ku, Sendai 980-8577, Japan \\ *Battery Production Engineering Development Div., Toyota Motor Corporation, 1200 Mishuku, Susono, Shizuoka 410-1193, Japan
}

$\mathrm{LiCoO}_{2}$ films were prepared on polycrystalline $\mathrm{Al}_{2} \mathrm{O}_{3}$ substrates by metal organic chemical vapor deposition (MOCVD), and the effect of the $\mathrm{Li}$ to Co source vapor ratio $\left(R_{\mathrm{Li} / \mathrm{Co}}\right)$ and substrate temperature $\left(T_{\text {sub }}\right)$ on the phases, orientation, morphology, and deposition rates were investigated. At $R_{\mathrm{Li} / \mathrm{Co}}>2.0, \mathrm{Li}_{2} \mathrm{CO}_{3}, \mathrm{Li}_{x} \mathrm{Co}_{1-x} \mathrm{O}$, and a $\mathrm{LiCoO}-\mathrm{CoO}$ solid solution were co-deposited with $\mathrm{LiCoO}_{2}$, whereas $\mathrm{Co}_{3} \mathrm{O}_{4}$ was co-deposited with $\mathrm{LiCoO}_{2}$ at $R_{\mathrm{Li} / \mathrm{Co}}<0.7$. Single-phase $\mathrm{LiCoO}_{2}$ films were obtained in the $R_{\mathrm{Li} / \mathrm{Co}}$ range of 0.7-2.0 at $T_{\text {sub }}>873 \mathrm{~K}$. Rutherford backscattering spectrometry revealed that single-phase $\mathrm{LiCoO}_{2}$ film had uniform and stoichiometric composition. The orientation of single-phase $\mathrm{LiCoO}_{2}$ films changed from (003) to (104) and (012) with increasing $T_{\text {sub }}$ at $R_{\mathrm{Li} / \mathrm{Co}} \sim 1.0$. $\mathrm{LiCoO}_{2}$ film co-deposited with $\mathrm{Co}_{3} \mathrm{O}_{4}$ at $R_{\mathrm{Li} / \mathrm{Co}}=0.4$ showed significant (101) orientation. The (003)-oriented $\mathrm{LiCoO}_{2}$ had a flat surface with hexagonal faceted texture, whereas the (101)- and (104)-oriented $\mathrm{LiCoO}_{2}$ had platelet grains in which the plate faces were tilted relative to the substrate surface. The highest deposition rate of single-phase $\mathrm{LiCoO}_{2}$ film was $10-20 \mu \mathrm{m} \mathrm{h}^{-1}$, which was 100 times greater than that reported in the literature.

(-2013 The Ceramic Society of Japan. All rights reserved.

Key-words : $\mathrm{LiCOO}_{2}$, Orientation, $\mathrm{LiCoO}_{2}-\mathrm{CO}_{3} \mathrm{O}_{4}$ composite, $\mathrm{Li}_{x} \mathrm{Co}_{1-x} \mathrm{O}$, Deposition rate

[Received December 18, 2012; Accepted January 18, 2013]

\section{Introduction}

Lithium cobaltate $\left(\mathrm{LiCoO}_{2}\right)$ cathode materials have exhibited high capacity and good reversibility in rechargeable $\mathrm{Li}$ ion batteries. ${ }^{1)}$ Because of the excellent electrochemical properties, $\mathrm{LiCoO}_{2}$ film has been extensively studied and fabricated for cathode film in all solid-state thin-film lithium-ion batteries for meeting the strict requirements of high power density and safety. ${ }^{2} \mathrm{LiCoO}_{2}$ has a rock-salt structure (space group: $R \overline{3} \mathrm{~m}$ ), in which the anions and cations form layers perpendicular to the $c$-axis direction. ${ }^{3)}$ The charging/discharging of $\mathrm{Li}^{+}$ions to and from the $\mathrm{LiCoO}_{2}$ cathode takes place two-dimensionally in the Li layer between the anion layers along the $c$-plane. ${ }^{4)}$ Hence, the orientation and morphology of the $\mathrm{LiCoO}_{2}$ films should be controlled for good transportations of $\mathrm{Li}^{+}$ions at interfaces between a cathode and an electrolyte.

Fabrication of $\mathrm{LiCoO}_{2}$ film has been reported by pulsed laser deposition (PLD), ${ }^{4)-6)}$ spray pyrolysis, ${ }^{7), 8}$ sputtering, ${ }^{9)-12)}$ chemical vapor deposition (CVD), ${ }^{13)-16)}$ and sol-gel synthesis. ${ }^{17), 18)}$ In general, $\mathrm{LiCoO}_{2}$ film is likely to grow in the $c$-axis direction because of the low surface energy of the (001) plane. ${ }^{12), 19)}$ However, the intercalation/deintercalation of $\mathrm{Li}^{+}$ions across the $(001)$ plane of $\mathrm{LiCoO}_{2}$ is rather difficult whereas that along the (001) plane can be easier. Therefore, non-(003) oriented $\mathrm{LiCoO}_{2}$ films have been fabricated by using the PLD and sputtering methods. Bates and Hart prepared (101)- and (104)oriented $\mathrm{LiCoO}_{2}$ films by RF magnetron sputtering after annealing. ${ }^{10), 12)} \mathrm{Xia}$ reported that $\mathrm{Li}^{+}$ion diffusivity in (104)-oriented $\mathrm{LiCoO}_{2}$ film prepared by PLD was ten times faster than that in a (003)-oriented film. ${ }^{4}$ Randomly oriented $\mathrm{LiCoO}_{2}$ films prepared by PLD had better charge/discharge capacities than (003)oriented films. ${ }^{20)}$

\footnotetext{
Corresponding author: H. Katsui; E-mail: katsui@imr.tohoku.ac.jp
}

The CVD technique allows the preparation of films at high deposition rates while controlling the morphology and orientation. The characteristics favor the fabrication of electrode films for high-capacity $\mathrm{Li}^{+}$ion batteries. ${ }^{21)}$ Although $\mathrm{Co}_{3} \mathrm{O}_{4}$ films with preferred orientation have been fabricated using $\mathrm{CVD},{ }^{22)-24)}$ there are few reports regarding the control of the orientation of $\mathrm{LiCoO}_{2}$ films by CVD. We reported (104)- and (018)-oriented $\mathrm{LiCoO}_{2}$ films deposited on $\mathrm{Al}_{2} \mathrm{O}_{3}$ and $\mathrm{MgO}$ single crystals by CVD, in which the orientation of $\mathrm{LiCoO}_{2}$ was dominated by the lattice matching to a plane of the single crystalline. ${ }^{25), 26)}$ Here, the CVD conditions such as deposition temperature and supply rates of precursor vapors affect the film structure as well as the phase formation, which is another approach to fabricate $\mathrm{LiCoO}_{2}$ films having a favorable orientation, irrespective of the crystal orientations of substrates. This study aims to prepare $\mathrm{LiCoO}_{2}$ and its composite films orientated not only to (003) but also to non-(003) such as (104) and (101) on polycrystalline substrates. We prepared $\mathrm{Li}-\mathrm{Co}-\mathrm{O}$ films on polycrystalline $\mathrm{Al}_{2} \mathrm{O}_{3}$ substrates by $\mathrm{CVD}$, and investigated the effect of the $\mathrm{Li}$ to Co source vapor ratio $\left(R_{\mathrm{Li} / \mathrm{Co}}\right)$ and substrate temperatures $\left(T_{\mathrm{sub}}\right)$ on the phase formation, orientation, morphology and deposition rates of the $\mathrm{Li}-$ Co-O films.

\section{Experimental}

Li-Co-O films were prepared in a vertical cold-wall type CVD chamber shown in Fig. 1. Li(DPM) (dipivaloylmethanatolithium) and $\operatorname{Co}(\mathrm{DPM})_{3}$ (tri-dipivaloylmethanato-cobalt) were used as precursors. The vaporization temperature of $\operatorname{Co}(\mathrm{DPM})_{3}$ was fixed at $465 \mathrm{~K}$, whereas that of $\mathrm{Li}(\mathrm{DPM})$ ranged from $517-$ $559 \mathrm{~K}$. The $R_{\mathrm{Li} / \mathrm{Co}}$ ranged from 0.4-5.0. The $\mathrm{Li}-$ and Co-source vapors were carried to the CVD reactor by Ar gas. Oxygen gas was separately supplied by a double-tube nozzle and mixed with the $\mathrm{Li}$ and $\mathrm{Co}$ source vapors above the substrate. The total gas flow rate was fixed at $3.3 \times 10^{-6} \mathrm{~m}^{3} \mathrm{~s}^{-1}$. A polycrystalline $\mathrm{Al}_{2} \mathrm{O}_{3}$ 


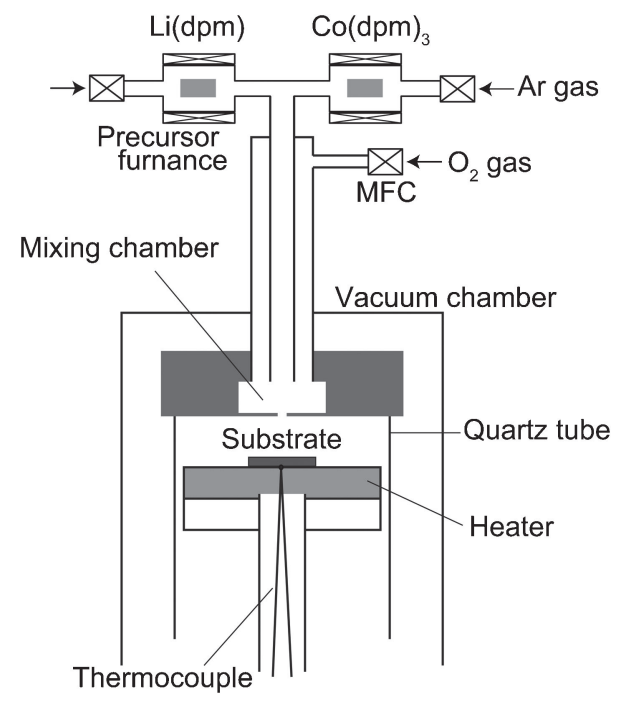

Fig. 1. Schematic of the CVD apparatus.

Table 1. Deposition conditions of $\mathrm{Li}-\mathrm{Co}-\mathrm{O}$ films

\begin{tabular}{ll}
\hline Vaporization temperature & \\
$\quad \mathrm{Li}(\mathrm{dpm})$ & $517-559 \mathrm{~K}$ \\
$\mathrm{Co}(\mathrm{dpm})_{3}$ & $465 \mathrm{~K}$ \\
$\mathrm{Ar}$ carrier gas flow rate & \\
$\quad$ for $\mathrm{Li} \mathrm{Li}(\mathrm{dpm})$ & $0.83 \times 10^{-6} \mathrm{~m}^{3} \mathrm{~s}^{-1}$ \\
for Co $(\mathrm{dpm})_{3}$ & $0.83 \times 10^{-6} \mathrm{~m}^{3} \mathrm{~s}^{-1}$ \\
$\mathrm{Li}$ to Co ratio $\left(R_{\mathrm{Li} / \mathrm{Co}}\right)$ & $0.4-5.0$ \\
$\mathrm{O}_{2}$ gas flow rate & $1.66 \times 10^{-6} \mathrm{~m}^{3} \mathrm{~s}^{-1}$ \\
$\mathrm{Substrate}$ & mirror-polished $\mathrm{Al}_{2} \mathrm{O}_{3}$ \\
Substrate temperature $\left(T_{\text {sub }}\right)$ & $523-1223 \mathrm{~K}$ \\
Total pressure $\left(P_{\text {tot }}\right)$ & $400 \mathrm{~Pa}$ \\
Distance between nozzle and substrate & $5 \mathrm{~mm}$ \\
Deposition time & $600-900 \mathrm{~s}$ \\
\hline
\end{tabular}

substrate $(99.5 \%$ purity; $10 \mathrm{~mm} \times 10 \mathrm{~mm} \times 1 \mathrm{~mm}$; Japan Fine Ceramics Co.) was set on a hot-stage, and $T_{\text {sub }}$ were monitored by a thermocouple. Li-Co-O films were deposited at $T_{\text {sub }}=523-$ $1223 \mathrm{~K}$. The total pressure in the CVD chamber $\left(P_{\text {tot }}\right)$ was fixed at $400 \mathrm{~Pa}$. The experimental conditions are summarized in Table 1.

The phases and orientation of $\mathrm{Li}-\mathrm{Co}-\mathrm{O}$ films were analyzed by X-ray diffraction $(\theta-2 \theta$ XRD, Rigaku RAD-2C). The compositional depth profiles of the $\mathrm{Li}-\mathrm{Co}-\mathrm{O}$ films was measured by Rutherford backscattering spectroscopy (RBS) using a $950 \mathrm{keV} \mathrm{H}^{+}$beam obtained from a 1.7 MV tandem accelerator. The RBS spectra were evaluated by using the computer code SIMNRA $6.0^{27)}$ where non-Rutherford cross sections were used for ${ }^{7} \mathrm{Li}(\mathrm{p}, \mathrm{p})^{7} \mathrm{Li}^{28)}$ and ${ }^{16} \mathrm{O}(\mathrm{p}, \mathrm{p})^{16} \mathrm{O} .{ }^{29)}$ The surface and crosssectional morphologies were observed by field emission-scanning electron microscopy (FE-SEM; JEOL, JSM-7500F). The deposition rate was calculated from the deposition time and thickness.

\section{Results and discussion}

Figure 2 depicts the effect of $R_{\mathrm{Li} / \mathrm{Co}}$ and $T_{\text {sub }}$ on the XRD patterns of $\mathrm{Li}-\mathrm{Co}-\mathrm{O}$ films. At $R_{\mathrm{Li} / \mathrm{Co}}=0.4$, spinel $\mathrm{Co}_{3} \mathrm{O}_{4}$ codeposited with $\mathrm{LiCoO}_{2}$ [Fig. 2(a)]. Single-phase $\mathrm{LiCoO}_{2}$ films were obtained at $R_{\mathrm{Li} / \mathrm{Co}}=0.9$ and 1.2 [Figs. 2(b) and 2(c)]. At $R_{\mathrm{Li} / \mathrm{Co}}=3.9$ [Fig. 2(d)], $\mathrm{LiCoO}_{2}$ and $\mathrm{Li}_{2} \mathrm{CO}_{3}$ were identified whereas the reflection peaks of $\mathrm{CoO}$ at $38.8,42.7$, and $62.0^{\circ}$ had shifted to higher angles than those of the powder pattern of CoO (JCPDS card No. 48-1719). It is known that Li and CoO can form $\mathrm{Li}_{x} \mathrm{Co}_{1-x} \mathrm{O}$ solid solutions with the rock-salt struc-

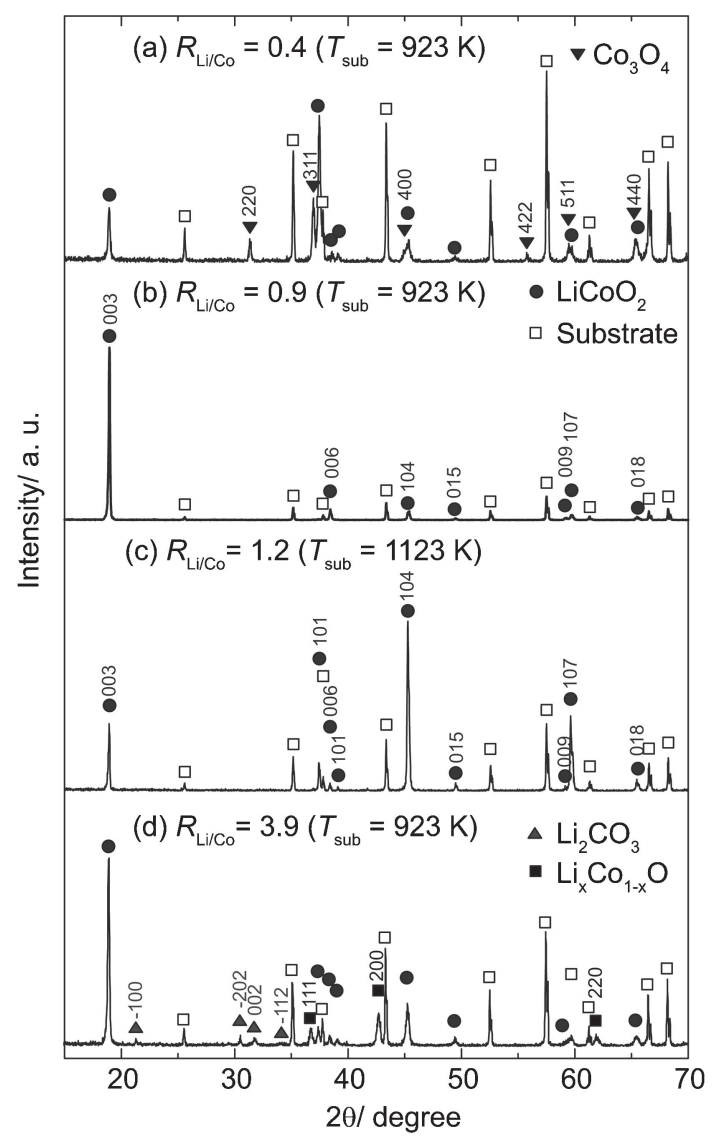

Fig. 2. Effect of $R_{\mathrm{Li} / \mathrm{Co}}$ and $T_{\text {sub }}$ on the XRD patterns of $\mathrm{Li}-\mathrm{Co}-\mathrm{O}$ films; (a) $R_{\mathrm{Li} / \mathrm{Co}}=0.4$ and $T_{\text {sub }}=923 \mathrm{~K}$, (a) $R_{\mathrm{Li} / \mathrm{Co}}=0.9$ and $T_{\text {sub }}=923 \mathrm{~K}$, (c) $R_{\mathrm{Li} / \mathrm{Co}}=1.2$ and $T_{\text {sub }}=1123 \mathrm{~K}$ and (d) $R_{\mathrm{Li} / \mathrm{Co}}=3.9$ and $T_{\text {sub }}=923 \mathrm{~K}$.

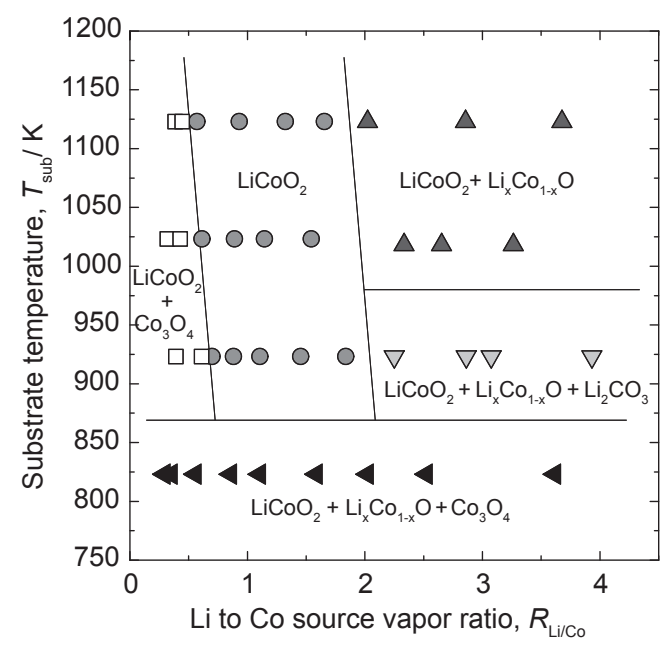

Fig. 3. Effect of $R_{\mathrm{Li} / \mathrm{Co}}$ and $T_{\text {sub }}$ on phases of $\mathrm{Li}-\mathrm{Co}-\mathrm{O}$ films.

ture. ${ }^{3), 21), 30)}$ Therefore, the reflection peaks of $\mathrm{CoO}$ were denoted as those of $\mathrm{Li}_{x} \mathrm{Co}_{1-x} \mathrm{O}$ in Fig. 2(d). The $x$ value in $\mathrm{Li}_{x} \mathrm{Co}_{1-x} \mathrm{O}$ was $0<x<0.2$. In $\mathrm{Li}-\mathrm{Co}-\mathrm{O}$ films, the $x$ value of $\mathrm{Li}_{x} \mathrm{Co}_{1-x} \mathrm{O}$ was estimated at $0.085-0.15$ from the lattice parameter of $\mathrm{Li}_{x} \mathrm{Co}_{1-x} \mathrm{O} .{ }^{3)}$ The effects of $R_{\mathrm{Li} / \mathrm{Co}}$ and $T_{\text {sub }}$ on the phase formation of $\mathrm{Li}-\mathrm{Co}-\mathrm{O}$ films are shown in Fig. 3. At $R_{\mathrm{Li} / \mathrm{Co}}>2.1$ and $T_{\text {sub }}=923 \mathrm{~K}$, a mixture of $\mathrm{LiCoO}_{2}, \mathrm{Li}_{2} \mathrm{CO}_{3}$, and $\mathrm{Li}_{x} \mathrm{Co}_{1-x} \mathrm{O}$ was obtained, whereas no $\mathrm{Li}_{2} \mathrm{CO}_{3}$ was identified at $T_{\text {sub }}>1023 \mathrm{~K}$. Since $\mathrm{Li}_{2} \mathrm{CO}_{3}$ is unstable and decomposes at $923 \mathrm{~K}$, the $\mathrm{Li}_{2} \mathrm{O}$ 


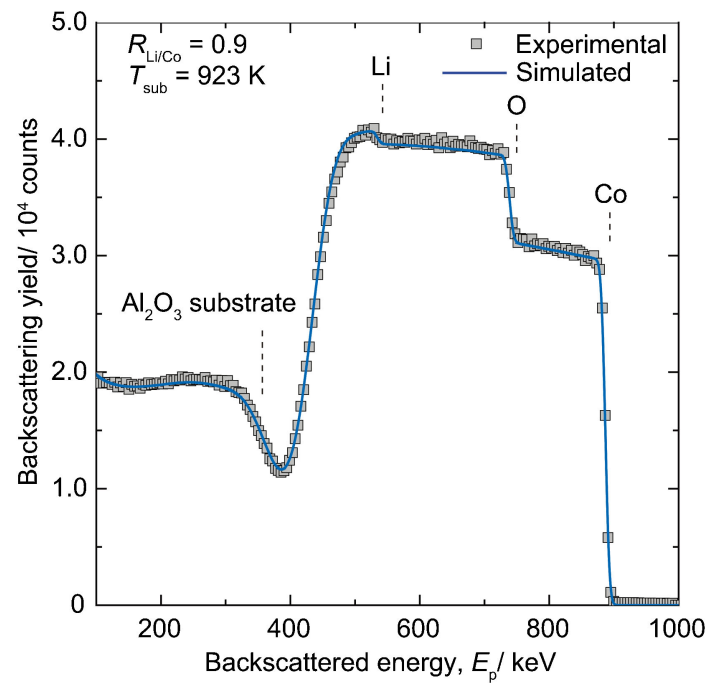

Fig. 4. RBS spectrum of $950 \mathrm{keV}$ protons incident on the $\mathrm{LiCoO}_{2}$ film prepared at $R_{\mathrm{Li} / \mathrm{Co}}=0.9$ and $T_{\text {sub }}=923 \mathrm{~K}$. The solid line is the simulation for the $\mathrm{LiCoO}_{2}$ film on $\mathrm{Al}_{2} \mathrm{O}_{3}$ substrate using SIMNRA code.

phase must have formed at $R_{\mathrm{Li} / \mathrm{Co}}>2.0$, and reacted with $\mathrm{CO}_{2}$ gas during the cooling process or after being exposed to air. $\mathrm{Li}_{2} \mathrm{CO}_{3}$ formation due to air exposure was reported in $\mathrm{Li}_{2} \mathrm{ZrO}_{3}$ and $\mathrm{Li}_{2} \mathrm{TiO}_{3} .{ }^{31)}$ At $R_{\mathrm{Li} / \mathrm{Co}}<0.5$ and $T_{\text {sub }}>923 \mathrm{~K}, \mathrm{Co}_{3} \mathrm{O}_{4}$ codeposited with $\mathrm{LiCoO}_{2}$. At $T_{\text {sub }}=823 \mathrm{~K}$, a mixture of $\mathrm{Co}_{3} \mathrm{O}_{4}$, $\mathrm{Li}_{x} \mathrm{Co}_{1-x} \mathrm{O}$ and $\mathrm{LiCoO}_{2}$ was deposited irrespective of $R_{\mathrm{Li} / \mathrm{Co}}$. A single-phase $\mathrm{LiCoO}_{2}$ film was obtained in the $R_{\mathrm{Li} / \mathrm{Co}}$ range from $0.5-2.0$ at $T_{\text {sub }}>923 \mathrm{~K}$. Figure 4 depicts the backscattering spectrum of the $\mathrm{LiCoO}_{2}$ film prepared at $R_{\mathrm{Li} / \mathrm{Co}}=0.9$. The backscattering yielded edges at 580,780 , and $940 \mathrm{keV}$ that corresponded to those of protons backscattered from $\mathrm{Li}, \mathrm{O}$, and $\mathrm{Co}$ atoms at the surface of the $\mathrm{LiCoO}_{2}$ film, respectively. The solid line is from the simulation of a stoichiometric $\mathrm{LiCoO}_{2}$ film, in which plural scattering is included. ${ }^{27)}$ The simulated areal density of $\mathrm{LiCoO}_{2}$ was $2.77 \times 10^{23}$ atoms $\mathrm{m}^{-2}$ and was converted to a thickness of $2.22 \mu \mathrm{m}$ assuming a density of $\mathrm{LiCoO}_{2}$ of 5.06 $\mathrm{Mg} \mathrm{m}^{-3}$. The experimental backscattering spectrum agreed well with the simulation, indicating that the $\mathrm{LiCoO}_{2}$ film had a uniform stoichiometric composition throughout the thickness. Since the source vapors, i.e., $\mathrm{Li}(\mathrm{DPM})$ and $\mathrm{Co}(\mathrm{DPM})_{3}$, contain hydrocarbon ligands, the presence of $\mathrm{C}$ impurities in $\mathrm{LiCoO}_{2}$ films is possible; however no increase in the backscattering yield of $\mathrm{C}$ was identified in the spectrum. Therefore, we inferred that the $\mathrm{LiCoO}_{2}$ film contained almost no $\mathrm{C}$ impurities.

A significantly high (003) reflection peak was observed in the $\mathrm{LiCoO}_{2}$ film prepared at $R_{\mathrm{Li} / \mathrm{Co}} \sim 1.0$ and $T_{\text {sub }}=923 \mathrm{~K}$ [Fig. 2(b)], whereas the (104) reflection was prominent at $T_{\text {sub }}=$ $1123 \mathrm{~K}$ [Fig. 2(c)]. The $\mathrm{LiCoO}_{2}$ film containing $\mathrm{Co}_{3} \mathrm{O}_{4}$ prepared at $R_{\mathrm{Li} / \mathrm{Co}}=0.4$ had a prominent (101) peak [Fig. 2(a)]. The orientation can be evaluated by the Harris texture coefficient (TC) using Eq. 1.32)

$$
T C(h k l)=N \frac{I_{m}(h k l) / I_{0}(h k l)}{\sum I_{m}(h k l) / I_{0}(h k l)}
$$

where $I_{m}(h k l)$ and $I_{0}(h k l)$ is the intensity from the $(h k l)$ plane, by measurement, and the powder pattern, respectively. (003), (101), (012), (104), and (018) peaks were used in the calculation $(N=5)$. $T C(h k l)$ values range between 0 and $N$, depending on the orientation of the $(h k l)$ plane. The $T C$ of a non-oriented plane

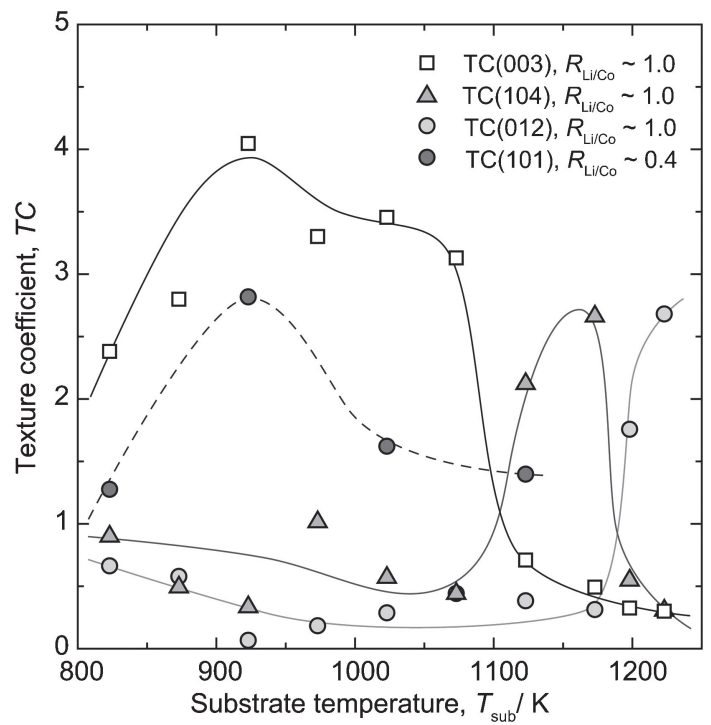

Fig. 5. Effect of $T_{\text {sub }}$ on orientations [TC(003), TC(104) and TC(012)] of single-phase $\mathrm{LiCoO}_{2}$ films at $R_{\mathrm{Li} / \mathrm{Co}} \sim 1.0$, and on $T C(101)$ of $\mathrm{LiCoO}_{2}$ for $\mathrm{LiCoO}_{2}-\mathrm{Co}_{3} \mathrm{O}_{4}$ composite films at $R_{\mathrm{Li} / \mathrm{Co}}=0.4$.

is 1.0. If the $T C(h k l)$ is more than 1.0 , the film can be defined as being partially oriented relative to the $(h k l)$ plane. Figure 5 depicts the effect of $T_{\text {sub }}$ on $T C(003), T C(104)$ and $T C(012)$ of the $\mathrm{LiCoO}_{2}$ films prepared at $R_{\mathrm{Li} / \mathrm{Co}} \sim 1.0$, and on $T C(101)$ of the $\mathrm{LiCoO}_{2}$ film containing $\mathrm{Co}_{3} \mathrm{O}_{4}$ prepared at $R_{\mathrm{Li} / \mathrm{Co}}=0.4$. The $T C(003)$ of $\mathrm{LiCoO}_{2}$ films prepared at $T_{\text {sub }}=823$ to $1073 \mathrm{~K}$ was 2.5 to 4 , indicating a significant $(003)$ orientation. At $T_{\mathrm{sub}}=$ $1123-1173 \mathrm{~K}$, the $\mathrm{LiCoO}_{2}$ films were oriented to (104) as the $T C(104)$ was $2-2.5$ and $T C(003)$ was lower than 1 . The $T C(012)$ reached 2.5 in the single-phase $\mathrm{LiCoO}_{2}$ film prepared at $T_{\text {sub }}=$ $1223 \mathrm{~K}$. The $T C(101)$ of the $\mathrm{LiCoO}_{2}$ film containing $\mathrm{Co}_{3} \mathrm{O}_{4}$ prepared at $R_{\mathrm{Li} / \mathrm{Co}}=0.4$ and $T_{\text {sub }} 923 \mathrm{~K}$ reached 2.9 .

Figure 6 depicts the typical surface morphology of (003)and (104)-oriented $\mathrm{LiCoO}_{2}$ films, and that of (101)-oriented $\mathrm{LiCoO}_{2}$ film containing $\mathrm{Co}_{3} \mathrm{O}_{4}$. Flat surface with hexagonal facets, which would reflect $c$-planes in the rhombohedral $\mathrm{LiCoO}_{2}$ lattice, were observed in the (003)-oriented film at $R_{\mathrm{Li} / \mathrm{Co}}=1.0$ and $T_{\text {sub }}=923 \mathrm{~K}$ (a). Rounded platelet grains were grown in the (104)-oriented $\mathrm{LiCoO}_{2}$ film at $R_{\mathrm{Li} / \mathrm{Co}}=1.2$ and $T_{\text {sub }}=1123 \mathrm{~K}$ (b). Elongated platelets with a thickness of several tens nm were observed (101)-oriented $\mathrm{LiCoO}_{2}$ film containing $\mathrm{Co}_{3} \mathrm{O}_{4}$ prepared at $R_{\mathrm{Li} / \mathrm{Co}}=0.4$ and $T_{\mathrm{sub}}=923 \mathrm{~K}(\mathrm{c})$. Given the lowest surface energy of the (003) plane forming the layer-stacking structure of $\mathrm{LiCoO}_{2}$, the rounded and elongated platelet facets [Figs. 6(b) and 6(c)] could be $(003) \mathrm{LiCoO}_{2}$ planes tilted at 55 and $79^{\circ}$ relative to the (104) and (101) planes. Further micro-structural analysis using a transmission electron microscope are still required to determine the detail textures.

Figure 7 depicts the effect of $T_{\text {sub }}$ on the deposition rates of Li-Co-O films compared with that reported by Cho and Yoon ${ }^{13)}$ in a Arrhenius format. Li-Co-O films were single-phase $\mathrm{LiCoO}_{2}$ at $T_{\text {sub }}>923 \mathrm{~K}$, a mixture of $\mathrm{Li}_{x} \mathrm{Co}_{1-x} \mathrm{O}, \mathrm{Co}_{3} \mathrm{O}_{4}$, and $\mathrm{LiCoO}_{2}$ at $T_{\text {sub }}=823-873 \mathrm{~K}$, and $\mathrm{CoO}$ at $T_{\text {sub }}<773 \mathrm{~K}$. The deposition rate linearly increased with increasing $T_{\text {sub }}$ below $773 \mathrm{~K}$ with activation energy of $34 \mathrm{~kJ} \mathrm{~mol}^{-1}$. The Arrhenius relationship between $T_{\text {sub }}$ and deposition rates implies that the film growth could be controlled by surface reaction forming $\mathrm{CoO}$ at $T_{\text {sub }}$ below $773 \mathrm{~K}$. Although there are no literature data on the activation energy of $\mathrm{CoO}$ formation on the substrate surface by 

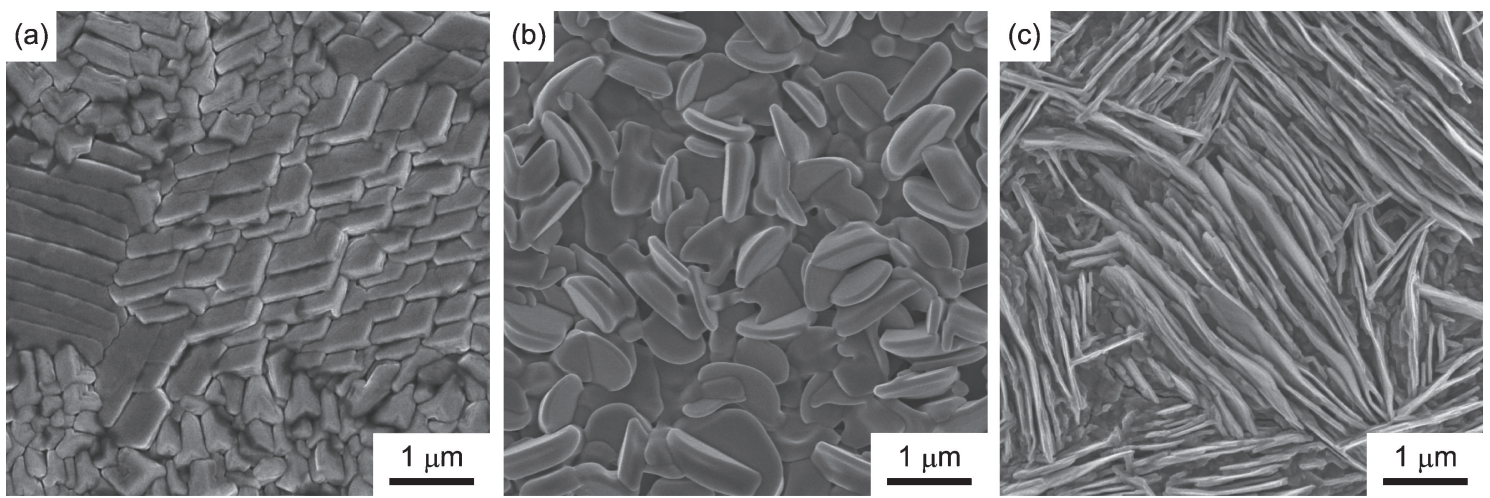

Fig. 6. Surface morphology of $\mathrm{LiCoO}_{2}$ films prepared at $R_{\mathrm{Li} / \mathrm{Co}} \sim 1.0$ and $T_{\text {sub }}=923$ (a) and $1123 \mathrm{~K}$ (b), and that of $\mathrm{LiCoO}_{2}$ films containing $\mathrm{Co}_{3} \mathrm{O}_{4}$ at $R_{\mathrm{Li} / \mathrm{Co}}=0.4$, and $T_{\text {sub }}=923 \mathrm{~K}$ (c).

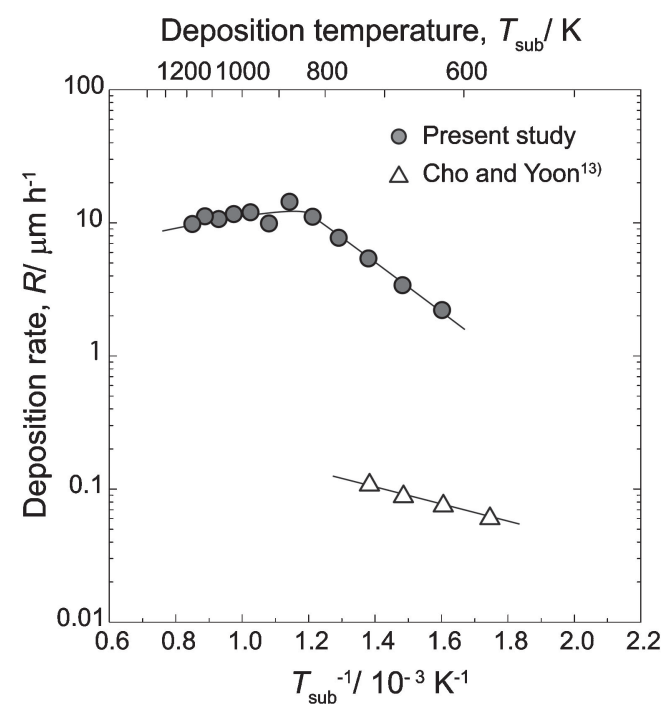

Fig. 7. Effect of $T_{\text {sub }}$ on the deposition rate of Li-Co-O film.

$\mathrm{CVD}$, the activation energy for the growth of $\mathrm{Co}_{3} \mathrm{O}_{4}$ was reported between 82 and $101 \mathrm{~kJ} \mathrm{~mol}^{-1}$.33)-35) The growth of a mixture of $\mathrm{CoO}$ and $\mathrm{Co}_{3} \mathrm{O}_{4}$ was reported to decrease the apparent activation energy to $47-58 \mathrm{~kJ} \mathrm{~mol}^{-1}$. ${ }^{36)}$ Hence, the activation energy for the formation of single-phase $\mathrm{CoO}$ is expected to be lower than $\mathrm{Co}_{3} \mathrm{O}_{4}$, which is consistent with the present value of $34 \mathrm{~kJ} \mathrm{~mol}^{-1}$. In the high $T_{\text {sub }}$ region $\left(T_{\text {sub }}>800 \mathrm{~K}\right)$ in which $\mathrm{LiCoO}_{2}$ formed, the deposition rates became almost constant or slightly decreased (Fig. 7). It is commonly understood that chemical reactions are fast enough at high temperatures and the deposition rates are limited by mass transfer (diffusion) in the gas phase and depended less on temperature. ${ }^{37)}$ Homogeneous reactions in the gas phase would be also attributed to the slight decrease in the deposition rates at $T_{\text {sub }}>900 \mathrm{~K} .^{38)}$ The deposition rate for singlephase $\mathrm{LiCoO}_{2}$ at $T_{\text {sub }}>923 \mathrm{~K}$ was approximately $10-20 \mu \mathrm{m} \mathrm{h}^{-1}$ which is 100 times higher than that reported by Cho and Yoon. ${ }^{13)}$ These authors prepared (003)-oriented $\mathrm{LiCoO}_{2}$ films and regarded the limiting factor in $\mathrm{LiCoO}_{2}$ formation as mass transfer in the gas phase since the deposition rate did not depend on the deposition temperature (activation energy: $14 \mathrm{~kJ} \mathrm{~mol}^{-1}$ ). While the temperature range of $\mathrm{LiCoO}_{2}$ formation in their work was from $573-723 \mathrm{~K}$, which is lower than that in the present study, we found that the preferred orientation of $\mathrm{LiCoO}_{2}$ changed from (003) to (104) at $T_{\text {sub }} \sim 1100 \mathrm{~K}$ (Fig. 5). The difference in the deposition rate and temperature range for $\mathrm{LiCoO}_{2}$ formation between the present study and the report of Cho and Yoon could be caused by the CVD regime, i.e., precursors, delivery system of the precursors to substrates and deposition pressure. Note that $\mathrm{Li}\left(\mathrm{TMHD}\right.$ ), (TMHD: $\mathrm{C}_{11} \mathrm{H}_{19} \mathrm{O} 2,2,2,6,6$-tetramethyl-3,5heptanedionate), and $\mathrm{Co}(\mathrm{TMHD})_{3}$ were dissolved in an organic solvent and evaporated using a vaporizer, and the deposition pressure was at $133 \mathrm{~Pa}$ in their work. ${ }^{13)}$

\section{Conclusions}

We prepared single-phase $\mathrm{LiCoO}_{2}$ and its composite films with $\mathrm{Co}_{3} \mathrm{O}_{4}$ and $\mathrm{Li}_{x} \mathrm{Co}_{1-x} \mathrm{O}$ on polycrystalline $\mathrm{Al}_{2} \mathrm{O}_{3}$ substrates by metal organic CVD. At $R_{\mathrm{Li} / \mathrm{Co}}>2.0$ and $T_{\text {sub }}>900 \mathrm{~K}, \mathrm{Li}_{2} \mathrm{CO}_{3}$ and $\mathrm{Li}_{x} \mathrm{Co}_{1-x} \mathrm{O}$ were co-deposited with $\mathrm{LiCoO}_{2}$, whereas the composite of $\mathrm{LiCoO}_{2}$ and $\mathrm{Co}_{3} \mathrm{O}_{4}$ was deposited at $R_{\mathrm{Li} / \mathrm{Co}}<0.7$. Single-phase $\mathrm{LiCoO}_{2}$ films having uniform stoichiometric composition in the growth direction without $\mathrm{C}$ impurities were obtained in the $R_{\mathrm{Li} / \mathrm{Co}}$ range of $0.7-2.0$ at $T_{\text {sub }}>900 \mathrm{~K}$. The orientation of single-phase $\mathrm{LiCoO}_{2}$ films changed from (003) to (104) and to (012) with increasing $T_{\text {sub }}$. The $\mathrm{LiCoO}_{2}$ co-deposited with $\mathrm{Co}_{3} \mathrm{O}_{4}$ prepared at $R_{\mathrm{Li} / \mathrm{Co}}=0.4$ showed (101) orientation. The (003)-oriented $\mathrm{LiCoO}_{2}$ had a flat surface with hexagonal faceted texture, whereas rounded platelet grains were observed in the (104)-oriented $\mathrm{LiCoO}_{2}$ film. The texture of (101)-oriented $\mathrm{LiCoO}_{2}$ co-deposited with $\mathrm{Co}_{3} \mathrm{O}_{4}$ was characterized by elongated platelets tilted relative to the substrate surface, reflecting the layered crystal structure of $\mathrm{LiCoO}_{2}$. The deposition rate for single-phase $\mathrm{LiCoO}_{2}$ was $10-20 \mu \mathrm{mh}^{-1}$, which was hundred times more than the value reported in the literature.

Acknowledgement This work was supported by the MEXT (Ministry of Education, Culture, Sports, Science and Technology), Grant-in-Aid for Young Scientists (B) No. 24760558, and a cooperative program of the ARCMG-IMR, Tohoku University.

\section{References}

1) P. Fragnaud, T. Brousse and D. Schleich, J. Power Sources, 63, 187-191 (1996).

2) N. Kuwata, J. Kawamura, K. Toribami, T. Hattori and N. Sata, Electrochem. Commun., 6, 417-421 (2004).

3) W. D. Johnston, R. R. Heikes and D. Sestrich, J. Phys. Chem. Solids, 7, 1-13 (1958).

4) H. Xia and L. Lu, Electrochim. Acta, 52, 7014-7021 (2007).

5) M. C. Rao, J. Cryst. Growth, 312, 2799-2803 (2010).

6) P. J. Bouwman, B. A. Boukamp, H. J. M. Bouwmeester, H. J. Wondergem and P. H. L. Notten, J. Electrochem. Soc., 148, A311-A317 (2001).

7) E. M. K. C. H. Chen, A. A. J. Buysman and J. Schoonman, 
Solid State Ionics, 80, 1-4 (1995).

8) H. S. W. Chang, T. J. Lee, S. C. Lin and J. H. Jeng, J. Power Sources, 54, 403-405 (1995).

9) J. B. Bates, N. J. Dudney, B. J. Neudecker, F. X. Hart, H. P. Jun and S. A. Hackney, J. Electrochem. Soc., 147, 59-70 (2000).

10) B. Wang, J. B. Bates, F. X. Hart, B. C. Sales, R. A. Zuhr and J. D. Robertson, J. Electrochem. Soc., 143, 3203-3213 (1996).

11) C. Liao, Y. Lee and K. Fung, J. Alloys Compd., 436, 303-308 (2007).

12) F. X. Hart and J. B. Bates, J. Appl. Phys., 83, 7560-7566 (1998).

13) S. I. Cho and S. G. Yoon, J. Electrochem. Soc., 149, A1584A1588 (2002).

14) S. I. Cho and S. G. Yoon, Appl. Phys. Lett., 82, 3345-3347 (2003).

15) J. F. M. Oudenhoven, T. van Dongen, R. A. H. Niessen, M. H. J. M. de Croon and P. H. L. Notten, J. Electrochem. Soc., 156, D169-D174 (2009).

16) W. G. Choi and S. G. Yoon, J. Power Sources, 125, 236-241 (2004).

17) Z. S. Peng, C. R. Wan and C. Y. Jiang, J. Power Sources, 72, 215-220 (1998).

18) T. Matsushita, K. Dokko and K. Kanamura, J. Electrochem. Soc., 152, A2229-A2237 (2005).

19) J. D. Perkins, C. S. Bahn, P. A. Parilla, J. M. McGraw, M. L. $\mathrm{Fu}$, M. Duncan, H. Yu and D. S. Ginley, J. Power Sources, 8182, 675-679 (1999).

20) S. Tang, M. Lai and L. Lu, J. Alloys Compd., 424, 342-346 (2006).

21) P. Fragnaud, R. Nagarajan, D. Schleich and D. Vujic, J. Power Sources, 54, 362-366 (1995).

22) D. Barreca and C. Massignan, Chem. Mater., 13, 588-593 (2001).

23) D. Barreca, E. Comini, A. Gasparotto, C. Maccato, A. Pozza,
C. Sada, G. Sberveglieri and E. Tondello, J. Nanosci. Nanotechnol., 10, 8054-8061 (2010).

24) D. Barreca, P. Fornasiero, A. Gasparotto, V. Gombac, C. Maccato, A. Pozza and E. Tondello, Chem. Vap. Deposition, 16, 296-300 (2010).

25) H. Katsui, Y. Yamashita and T. Goto, Key Eng. Mater, 508, 300-303 (2012).

26) H. Katsui and T. Goto, Surf. Coat. Technol., 218, 57-61 (2013).

27) M. Mayer, SIMNRA User's Guide 6.05, Max-Planck-Institut für Plasmaphysik, Garching (2009).

28) W. Warters, W. Fowler and C. Lauritsen, Phys. Rev, 91, 917921 (1953).

29) A. Gurbich, Nucl. Instrum. Methods Phys. Res., Sect. B, 129, 311-316 (1997).

30) R. J. Moore and J. White, J. Mater. Sci., 9, 1401-1408 (1974).

31) H. Katsui, S. Nagata, B. Tsuchiya and T. Shikama, Nucl. Instrum. Methods Phys. Res., Sect. B 272, 275-279 (2012).

32) C. S. Barret and T. B. Massalski, Structure of Metals, Pergamon Press, Oxford (1980).

33) D. Barreca, A. Gasparotto, O. Lebedev, C. Maccato, A. Pozza, S. Turner and G. Tendeloo, CrystEngComm, 12, 2185-2197 (2010).

34) N. Bahlawane, E. F. Rivera, K. Kohse-Höinghaus, A. Brechling and U. Kleineberg, Appl. Catal., B, 53, 245-255 (2004).

35) A. U. Mane, K. Shalini, A. Wohlfart, A. Devi and S. A Shivashankar, J. Cryst. Growth, 240, 157-163 (2002).

36) A. U. Mane and S. A. Shivashankar, J. Cryst. Growth, 254, 368-377 (2003).

37) M. Hampden-Smith and T. Kodas, Chem. Vap. Deposition, 1, 8-23 (1995).

38) M. Pulver, W. Nemetz and G. Wahl, Surf. Coat. Tech., 125, $400-406$ (2000). 